\title{
SES GRADIENTS IN HEALTH
}

\section{Health and Wealth among the Poor: India and South Africa Compared}

\author{
By Anne Case and Angus Deaton*
}

Health and wealth are the two most important components of well-being. Rankings of wellbeing based on income will differ from more comprehensive rankings, depending on the way that income and health are related. There are strong bidirectional causal links between income and health so that we cannot understand either without understanding both. What we call the "wealthier is healthier" hypothesis asserts both that income is the main determinant of health and that the international correlation between income and health is sufficiently tight for income rankings to indicate well-being more broadly (see e.g., Richard G. A. Feachem [2001] who, like many researchers, cites Lant Pritchett and Lawrence H. Summers [1996] on the causal role of income in protecting health). Comparisons between India and South Africa provide a good illustration of both the usefulness and the complexities of working with both health and wealth. In 2000, India's per capita income was $\$ 2,045$ in (chained) purchasing power parity (PPP) dollars, less than a third of South Africa's, \$7,409. Even if we adjust the latter figure for the distribution of income between whites and Africans in South Africa, Africans in South Africa are at least 50 percent better off than Indians in terms of GDP per

\footnotetext{
† Discussants: Amitabh Chandra, Dartmouth College; Tomas Philipson, University of Chicago; Angus Deaton, Princeton University.

* Research Program in Development Studies and Center for Health and Wellbeing, Princeton University, NJ 08544, USA. We gratefully acknowledge funding from the $\mathrm{Na}$ tional Institute on Aging R01 AG20275-01 and the MacArthur Foundation ("Research Network on Poverty and Inequality in a Broader Perspective"). A fuller version of this paper, including supporting tables and information on the Khayelitsha survey design, is available at $\langle\mathrm{http} / / \mathrm{www}$. wws.princeton.edu/ rpds $\rangle$.
}

capita. Yet life expectancy in South Africa, which in 1990 was three years longer than in India, by 2000 was 14 years shorter; and the reversal is even more dramatic if South African whites are excluded. In this paper, we report direct comparisons of a number of objective and subjective measures of economic and health status in two sites, one in the district of Udaipur in rural Rajasthan, and one in the shack township of Khayelitsha near Cape Town. We are interested in an assessment of the "wealthier is healthier" hypothesis and, more generally, in the feasibility of making international comparisons of well-being using individual-level data, and especially the use of subjective measures of health and living standards (i.e., whether they reflect objective measures, or are fully adapted to local expectations). Our results show that the economically better-off South Africans are healthier in some respects, but not in others. They are taller and heavier, but their self-assessed health is no better; they suffer from depression and anxiety to about the same degree; they have a remarkably similar pattern of prevalence of various health conditions; and both adults and children in South Africa are more likely to go without food for lack of money. Even if some of the self-reported deprivations, such as hunger, are assessed relative to different local expectations, the effects on anxiety and mental health are absolute and absolutely comparable. Because health, like well-being, is multidimensional, and because the components of health do not correlate perfectly with one another, nor with income-based measures, income on its own is likely to be misleading as a shortcut measure of international health. Even within places, such as the two examined here, the links between health and wealth are far from universally strong. 


\section{Health and Income in Khayelitsha and Udaipur}

We are here concerned with data from two poor populations. The first is a stratified sample of 1,000 households (more than 5,700 persons) in 100 villages in Udaipur district in India, carried out between August 2002 and August 2003, and described by Abhijit Banerjee et al. $(2004 a, b)$. The second survey of 300 households (1,243 persons) was collected between March and July 2003 from the shack township of Khayelitsha, near Cape Town. Almost all households in Khayelitsha have a family connection to the Eastern Cape (Transkei, Ciskei), from where their families recently migrated. Both survey instruments were designed to collect information on economic and health status, and while each was adapted to its own environment, the questionnaires were developed in parallel and contain many identical questions.

Our South African population is better educated, economically better-off, and better nourished. Mean monthly total expenditure per head is estimated to be 220 PPP (2003) dollars per head in Khayelitsha but only 42.8 PPP dollars per head in rural Udaipur. These estimates are likely noisy, but they are not wildly out of line with other survey evidence in India (\$52.7 [PPP] mean expenditures from the 2002-2003 round of the National Sample Survey in rural Rajasthan) and South Africa (\$289 [PPP] mean monthly income per household member, \$106 median, among Western Cape African households in the 2001 South African Census). The PPP value of food expenditure per head, which is probably more accurate, is more than three times as high in Khayelitsha as in Udaipur. The ownership of household durable goods is more widespread in the richer site; for a group of eight goods that appear in both surveys, the median number owned is one among the Indian households, and three among the South Africans. In Khayelitsha, four times as many households have electricity, and telephones (39 percent) and televisions (50 percent) are widespread, but these are rare in rural Udaipur (1 percent and 2 percent). Household respondents were also asked to rate their own economic status using a question of the form "How would this household classify its financial situation
Table 1-Self-Reported Financial Status in Udaipur AND KHAYELITSHA

\begin{tabular}{|c|c|c|c|c|}
\hline \multirow[b]{2}{*}{$\begin{array}{l}\text { Household } \\
\text { category }\end{array}$} & \multicolumn{2}{|c|}{ India } & \multicolumn{2}{|c|}{ South Africa } \\
\hline & Percentage & $\begin{array}{l}\text { Expenditure } \\
\text { (\$PPP) }\end{array}$ & Percentage & $\begin{array}{l}\text { Expenditure } \\
\text { (\$PPP) }\end{array}$ \\
\hline Wealthiest & 0.73 & - & 0 & - \\
\hline Second-highest & 1.67 & 62.8 & 1.0 & 596.9 \\
\hline Third-highest & 10.6 & 47.2 & 38.0 & 229.3 \\
\hline Fourth-highest & 32.2 & 38.7 & 44.0 & 161.3 \\
\hline Poorest & 54.8 & 31.2 & 17.0 & 121.7 \\
\hline $\begin{array}{l}\text { Number of } \\
\text { observations: }\end{array}$ & 1,022 & 1,022 & 300 & 300 \\
\hline
\end{tabular}

Notes: The percentage of households reporting each category is shown, along with median expenditure per person (in PPP dollars).

these days?" using a ten-rung ladder in India, and a five-point scale in Khayelitsha. Table 1 shows that these responses are well correlated with measured expenditure per capita and that the Indian households (correctly) characterized themselves as very poor relative to the Africans. Even so, the Indian and African respondents are clearly not using the same (PPP) scale; even within the poorest category, median PPP expenditures per head are four times larger in Khayelitsha.

Until recently, women in rural Rajasthan did not go to school, and more than 90 percent of the women in our sample are illiterate. Although almost half of all men can read and write, average completed education is less than three years. The population of Khayelitsha is better educated, although only by comparison. Although both men and women have more than six years of schooling on average, more than half of all women and a quarter of men report themselves to be illiterate.

South Africans are taller $(3 \mathrm{~cm}$ for men, $5 \mathrm{~cm}$ for women) and heavier. But it is weight for height (the body mass index, or BMI) that shows the largest difference across the two sites. Sixty-three percent of men and 57 percent of women in rural Udaipur have a BMI of less than 18.5, which is the international cutoff for underweight (WHO Expert Consultation, 2004). Few of the South Africans are underweight, but 75 percent of the women are stage 2 (BMI between 25 and 30) or stage 3 (BMI over 30; obese). This is consistent with results found for a much larger, nationally representative sample of Africans measured in the 1998 South African 
TABLE 2-Individual ChaRACTERISTICS

\begin{tabular}{|c|c|c|c|c|}
\hline \multirow[b]{2}{*}{ Measure } & \multicolumn{2}{|c|}{ India } & \multicolumn{2}{|c|}{ South Africa } \\
\hline & Men & Women & Men & Women \\
\hline \multicolumn{5}{|l|}{ Anthropometrics: } \\
\hline $\begin{array}{l}\text { Mean height }(\mathrm{cm}) \\
\text { (SD) }\end{array}$ & $\begin{array}{l}164 \\
(7.6)\end{array}$ & $\begin{array}{l}152 \\
(7.9)\end{array}$ & $\begin{array}{l}167 \\
(12.7)\end{array}$ & $\begin{array}{l}157 \\
(7.9)\end{array}$ \\
\hline $\mathrm{BMI} \leq 18.5$ & 62.7 & 56.8 & 7.2 & 1.5 \\
\hline $25 \leq \mathrm{BMI}<30$ & 0.6 & 1.6 & 19.1 & 27.2 \\
\hline $30 \leq \mathrm{BMI}<40$ & 0.1 & 0.3 & 5.1 & 36.4 \\
\hline $40 \leq \mathrm{BMI}$ & 0.2 & 0.2 & 1.7 & 11.5 \\
\hline \multicolumn{5}{|l|}{ Self-Reported Health: } \\
\hline 1) Excellent & 12.4 & 8.7 & 18.5 & 10.4 \\
\hline 2) Very good & 31.9 & 26.5 & 24.2 & 21.0 \\
\hline 3) Good & 33.2 & 32.0 & 32.1 & 33.9 \\
\hline 4) Fair & 15.6 & 25.4 & 18.2 & 25.1 \\
\hline 5) Poor & 6.9 & 7.4 & 7.0 & 9.6 \\
\hline Mean & 2.73 & 2.96 & 2.71 & 3.03 \\
\hline \multicolumn{5}{|l|}{ Blood Pressure: } \\
\hline Normal & 55.0 & 61.0 & 48.7 & 45.3 \\
\hline High-normal & 25.1 & 23.0 & 24.7 & 24.4 \\
\hline Stage-1 hypertensive & 14.0 & 10.3 & 17.6 & 17.9 \\
\hline Stage-2 hypertensive & 3.8 & 4.2 & 6.1 & 8.3 \\
\hline Stage 3 or higher & 2.0 & 1.5 & 3.0 & 4.2 \\
\hline
\end{tabular}

Notes: Except for the top two rows and the means for self-reported health, all entries are percentages. Values in parentheses are standard deviations for the height means.

Demographic and Health Survey (see Thandi Puoane et al., 2002). Hypertension, in part associated with obesity, is also more prevalent among the South Africans, and somewhat more prevalent among the women than the men within Khayelitsha, although perhaps less than might be expected given the gender differences in obesity (see Table 2). South African townships are already suffering from the posttransitional health problems of diabetes and stroke, which have yet to make an appearance in rural Rajasthan.

Table 2 also shows the distribution of selfreported health status on a standard five-point scale in which larger numbers indicate worse health. These distributions are remarkably similar across the two sites, but this surely reflects adaptation or lower health expectations in India and can hardly be taken as an exception to the "wealthier is healthier" rule. Self-reported health status is adapted to people's circumstances, and indeed there are many examples within countries of poorer people reporting less morbidity than richer people, in spite of a great deal of evidence to the contrary. (But note that the Indian respondents have no difficulty in selfassessing themselves as poor, though they do not perceive themselves as sick. Perhaps poverty is more readily observable than at least some dimensions of health.)

Using simplified versions of the USDA's questions for measuring food insecurity, household respondents were asked whether there had been a time in the last year when, because of lack of money, an adult missed a meal, or had not eaten for a whole day, or whether a child had missed a meal. In spite of (or conceivably because of) their apparently better nutrition, Africans reported that adults missed meals twice as frequently and went whole days without food more than twice as frequently, and that children went without food nearly four times as frequently as did the Indian children. While it is possible that these results have something to do with the difference between an urban, moremonetized environment versus an agricultural, less-monetized environment, anecdotal clinical evidence from Khayelitsha maintains that child malnourishment is common and is often associated with maternal obesity. Comparisons of child anthropometrics by age across the two sites show very similar growth charts, so that the under-nutrition of children appears to be as prevalent in Khayelitsha as it is in Udaipur. While these measurements would support equal degrees of hunger for children in both sites, they do nothing to provide an objective explanation for the much greater hunger reported among both children and adults in Khayelitsha, and they stand in stark contrast to the superiority of the South Africans in both income and physical stature.

Figure 1 shows the prevalence of 22 health conditions that were asked about in both surveys. For the majority of these, prevalence is higher in South Africa, though more notable is the similarity between the two very different sites. The correlation across the reported health conditions in the figure is 0.84 . We also included in both sites questions on depression and anxiety. Substantial percentages of men and women in both sites (30.8 percent of men and 24.3 percent of women in India, and 22.3 percent of men and 30.9 percent of women in South Africa) reported that over the last year they had had a period of a month or longer 


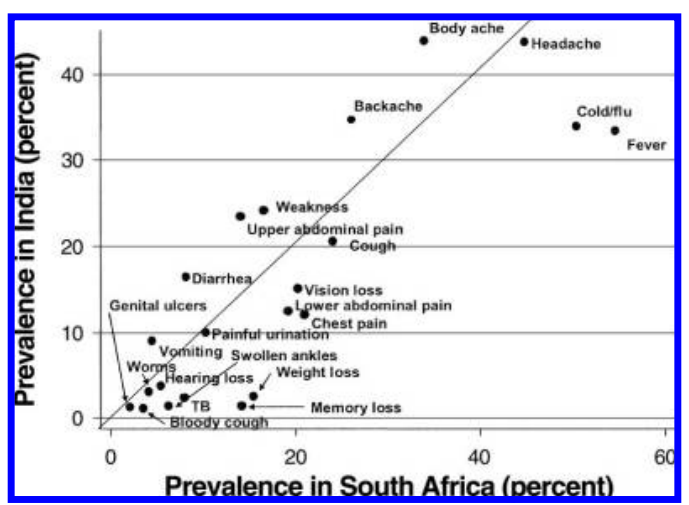

Figure 1. Prevalence of Common Conditions, Udaipur Villages and Khayelitsha

during which they worried most of the time, and of those, between 38 and 52 percent said that this worrying had significantly interfered with their normal activities. Similarly, indicators of depression (feeling sad, crying a lot, not feeling like eating) were prevalent in both sites, with no evidence of better mental health among the bettereducated and better-off South Africans.

\section{The Correlates of Health}

One way to calibrate the effects of health conditions is to examine their impact on selfreported health status. We can also look at the gradient, the extent to which living standards or education protect health directly or moderate the effects of various health impairments. To do this, we ran regressions of self-reported health status on the presence of the health conditions in Figure 1, separately and together, with and without variables for education and for economic status. We also examined the relationship between the conditions and the household socioeconomic variables, in order to test whether education and income reduce the likelihood of having these health conditions.

In all of our regressions, women have worse self-reported health status than men; this effect, which is about 0.25 of a unit on a five-point scale, is robust to controlling for age, socioeconomic status, and health conditions. Being literate improves self-reported health status for women, and by the same amount in both sites, about 0.25 of a point on a five-point scale. There is no effect of literacy on self-reported health status for men. In India, the number of durable goods possessed significantly improves selfreported health status, while household total expenditure per head (or food expenditure per head) does not; the reverse is true in South Africa. In all of the regressions, in both sites, virtually all health conditions have a significant deleterious effect on self-reported health status, whether or not we control for household expenditures, assets, or education; the exceptions, where there is no significant effect, are relatively rare conditions, like memory loss for women (but not men) and genital ulcers for men (but not women) in India, and genital ulcers, worms, cough with blood, and vomiting for women in South Africa. When all health conditions are jointly regressed on self-reported health status, the coefficients are around onethird smaller than when they are regressed one at a time, as is to be expected given co-morbidities. The effects of each condition on self-reported health are typically somewhat larger in India than in South Africa and are only weakly correlated (0.3) across the two sites; for example, weight loss and a cough with blood have much larger effects on health status in Udaipur, while the reverse is true for hearing and vision problems and for diarrhea, which is much more prevalent among the Indians.

When health conditions are aggregated into an index of the number of health conditions, selfreported health status worsens by a little more than 0.1 unit for each additional health condition, in both sites. The effect of the index on health status is not modified by any of the socioeconomic status measures, so that there is no evidence that betteroff or more-educated people suffer less than poorer or less-educated people, conditional on having one of the health conditions. In India, the numbers of health conditions are not significantly associated with education, household expenditures, or number of assets, once we control for age, so that prevalence of morbidities does not appear to be lower among the better-off in Udaipur. In South Africa, expenditure per member (but neither literacy nor assets owned) predicts a lower number of symptoms, with a doubling of income associated with a 0.3 reduction in the number of conditions reported. In general, the 
favorable effects of education and either assets or total expenditure on health status appear to be direct effects and do not operate either on reducing morbidity or on reducing the consequences of morbidity, once established.

In both communities, the presence of hunger, in the form of reports of meals missed for lack of money by either adults or children, has a powerful effect on reported depression. In India, the probability of reporting a prolonged period of worry or anxiety is increased by 10 percent if any adult in the household has gone for a whole day without food, and by a further 15 percent if it is reported that a child missed a meal.

\section{REFERENCES}

Banerjee, Abhijit; Deaton, Angus and Duflo, Esther. "Wealth, Health, and Health Services in Rural Rajasthan." American Economic Review, 2004a (Papers and Proceedings), 94(2), pp. 326-30.
Banerjee, Abhijit; Deaton, Angus and Duflo, Esther. "Health Care Delivery in Rural Rajasthan." Economic and Political Weekly, February 28, 2004b, pp. 944-49.

-Feachem, Richard G. A. "Globalisation Is Good for Your Health, Mostly." British Medical Journal, 2001, 323(7311), pp. 504-6.

-Pritchett, Lant and Summers, Lawrence $H$. "Wealthier Is Healthier." Journal of Human Resources, 1996, 31(4), pp. 841-68.

-Puoane, Thandi; Steyn, Krisela; Bradshaw, Debbie; Laubscher, Ria; Fourie, Jean; Lambert, Vicki and Mbananga, Nolwazi. "Obesity in South Africa: The South African Demographic and Health Survey." Obesity Research, 2002, 10(10), pp. 103848.

-WHO Expert Consultation. "Appropriate BodyMass Index for Asian Populations and Its Implications for Policy and Intervention Strategies." Lancet, 2004, 363(9403), pp. 157-63. 


\section{This article has been cited by:}

1. Fabrice Etilé, Carine Milcent. 2006. Income-related reporting heterogeneity in self-assessed health: evidence from France. Health Economics 15:9, 965-981. [CrossRef]

2. Angus Deaton. 2006. The Great Escape: A Review of Robert Fogel's The Escape from Hunger and Premature Death, 1700-2100The Great Escape: A Review of Robert Fogel's The Escape from Hunger and Premature Death, 1700-2100. Journal of Economic Literature 44:1, 106-114. [Abstract] [View PDF article] [PDF with links] 